\title{
Cyberheroes: An Interactive Ebook for Improving Children's Online Privacy
}

\author{
Leah Zhang-Kennedy \\ Carleton University \\ Ottawa, Canada \\ leah.zhang@carleton.ca
}

\author{
Sonia Chiasson \\ Carleton University \\ Ottawa, Canada \\ chiasson@scs.carleton.ca
}

\begin{abstract}
We designed, illustrated, and developed Cyberheroes, an educational interactive ebook that teaches children about online privacy. The ebook was evaluated with children and parents, and had positive effects on children's privacy knowledge, and improved their privacy-conscious behaviour.
\end{abstract}

Children; Education; Ebook; Privacy Human-Computer Interaction.

\section{ABOUT CYBERHEROES}

Cyberheroes is a children's educational interactive ebook about online privacy that we designed, illustrated, and implemented. Sample screens and interactive features are shown in Figure 1.

This Interactions Gallery exhibit includes some content from our paper "Cyberheroes: The design and evaluation of an interactive ebook to educate children about online privacy", to appear in the International Journal of Child-Computer Interaction.

The ebook was conceptualized based on the idea that Cyberheroes, like superheroes, have secret identities that they must protect. Due to the popularity of the superhero genre through comics and film, we believed the story would resonate with children and make the concept of privacy easy to understand. The story spans across 14 interactive screens and centres around two Cyberheroes, Ally and Bobby, who lost their cyberpowers and must face the consequences. The description of each cyberpower is a privacy-related lesson, summarized in Figure 1, D.

Children could read Cyberheroes online and download it on iPads. Children experience the interactive story through multitouch interaction that responds with voice audio, music, and animation. The interactive ebook takes approximately 5 to 8 minutes for children and parents to read together.

Our goals for the Cyberheroes interactive ebook are:

Educational: We assumed that our young audience has little to no experience about online privacy. Our aim was to gently introduce the concepts to children without technical and frightening details. Our previous work on children and parents' perceptions of mobile threats (Zhang-Kennedy et al. 2016) suggests that parents are mostly worried about children disclosing personal and location information, talking to strangers, cyberbullying, and poor management of passwords. Therefore, Cyberheroes focused on introducing children to these topics.

Entertaining: Since children mainly use mobile devices for entertainment, making the ebook fun and engaging was our second design goal. Privacy and security concepts in our interactive ebook are fully integrated into the story to make the educational content seamless from the narrative content. The story was designed to appeal to children with characters that are similar to them. The fantasy storybook illustration style is reminiscent of printed children's picture books. Interactive features in Cyberheroes show cause and effect relationships and consequences of the characters' actions. For example, the "chatting online" screen (Figure 1, B) shows that some people online are not who they say they are. When the user taps on the top right character, the image of 9-year-old "Alex" changes to 42-year-old "Mr. R". Ally responds to the change with a surprised expression and a shriek. The interactions prompt children to ask questions and discuss with parents about what is happening in the story.

Conversation-provoking: An early design decision we made was to include parents in children's learning process because our prior work (ZhangKennedy et al. 2016) showed that children often relied on parents for advice and guidance in their online interactions, suggesting that children's 


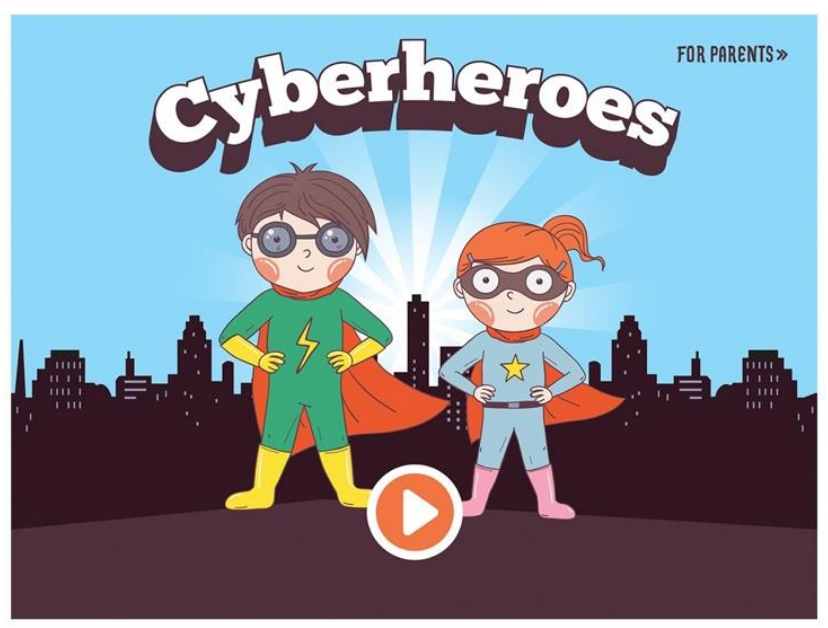

A.

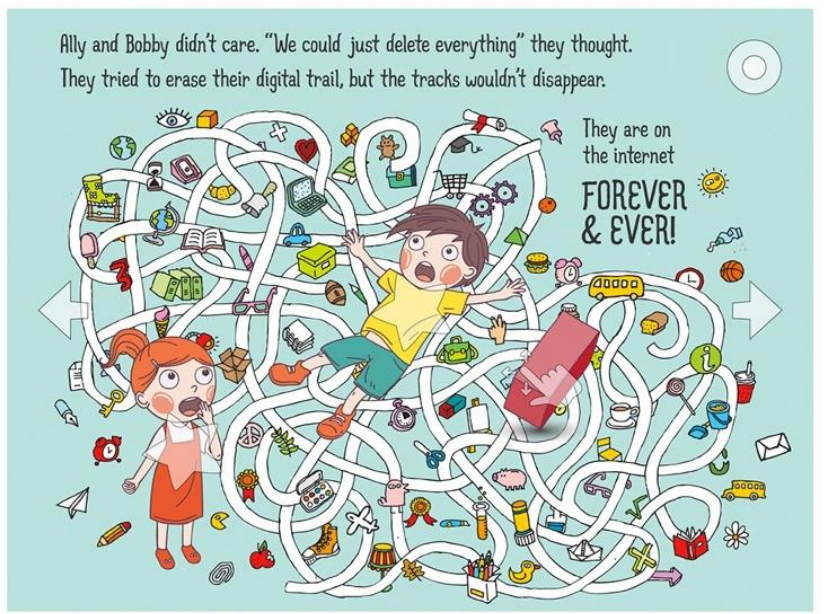

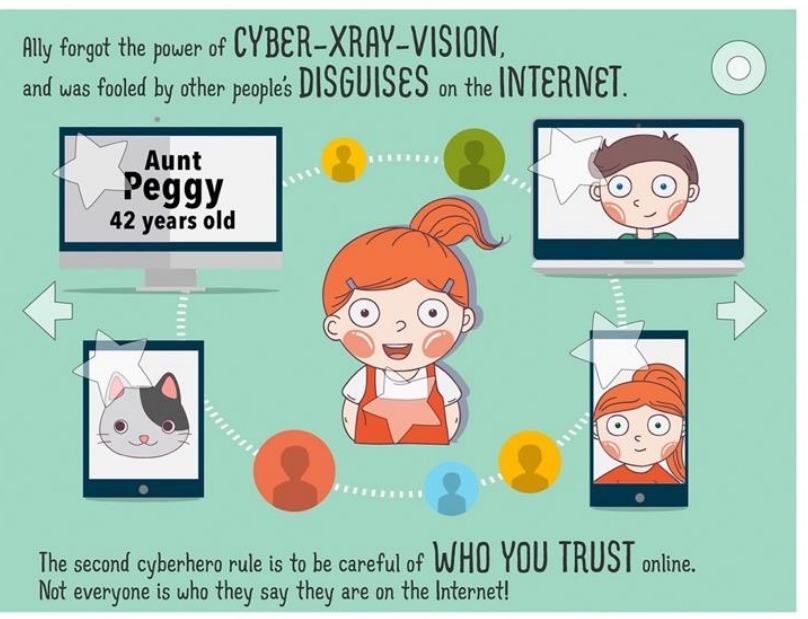

B.

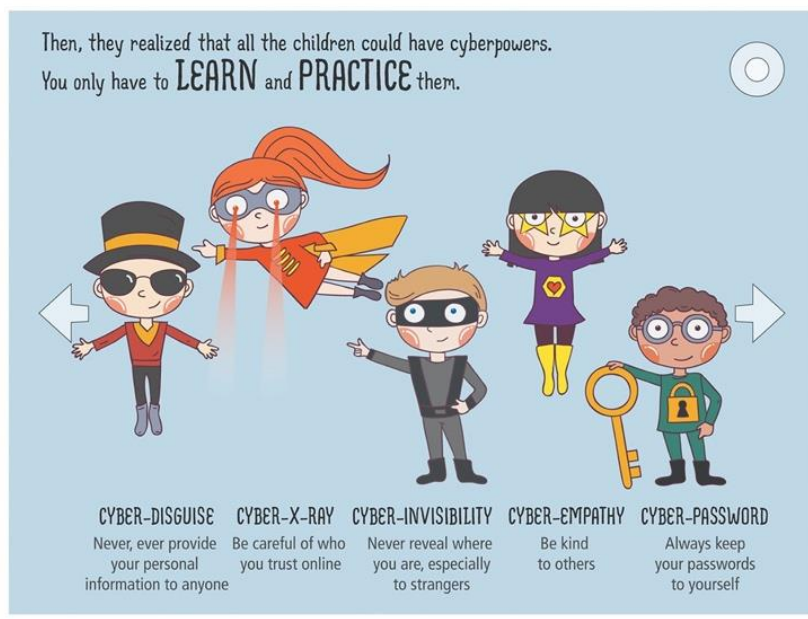

D.

Figure 1: Sample screens and interactions from Cyberheroes. A) Home Screen: the user presses the "play" button to start playing; B) Talking Online: the user taps on the screen characters to reveal their real identity, and Ally reacts; C) Digital Trail: the user drags the eraser over the digital trail to "erase" it, then the trail reappears; D) Cyberpowers: the user taps on each character to transform them into Cyberheroes (each has an animation and audio clip as they transform)

privacy and security education should involve parents in some way.

The ebook functioned as a facilitating tool between the parent and child to promote reflection and discussion around the subject of online privacy. Using the story as a starting point, we wanted the ebook to motivate families to link the subjects presented in the story to their real life experiences and extended the lessons using their own life stories. The intention is to help parents adapt the lessons to their family's needs, concerns, and context.

Our evaluation with children and parents (ZhangKennedy et al. 2017) showed that Cyberheroes increased children's privacy knowledge, sustained information retention, and promoted privacyconscious behaviour. Children and parents found Cyberheroes very engaging and fun to interact with.

\section{ABOUT THE AUTHORS}

Leah Zhang-Kennedy is the designer, illustrator, and developer of Cyberheroes. She has a Ph.D. in Computer Science and a MASc in Human-Computer Interaction $(\mathrm{HCl})$ from Carleton University, Canada.

Sonia Chiasson is the Canada Research Chair in Human Oriented Computer Security and a faculty member in the School of Computer Science at Carleton University, Canada.

\section{ACKNOWLEDGMENTS}

This project has been partially funded by the Office of the Privacy Commissioner of Canada (OPC); the 
views expressed herein are those of the authors and do not necessarily reflect those of the OPC.

\section{REFERENCES}

Cyberheroes are available online at: http://www.versipass.com/edusec/cyberheroes

Cyberheroes are available on ipads at: https://itunes.apple.com/ca/app/cyberheroes/id1 095724919 ? $\mathrm{mt}=8$

Zhang-Kennedy, L., Y. Abdelaziz, and S. Chiasson (2017). Cyberheroes: The design and evaluation of an interactive ebook to educate children about online privacy (to appear). International Journal of Child-Computer Interaction (IJCCI).

Zhang-Kennedy, L., C. Mekhail, Y. Abdelaziz, and S. Chiasson (2016). From nosy little brothers to stranger-danger: Children and parents' perception of mobile threats. In Interaction Design and Children, pp. 388-399. ACM. 